\title{
Exploring barriers to long-term follow-up in newborn screening programs
}

Timothy Hoff, $P h D^{1}$, Adrienne Hoyt, $M P H^{1}$, Brad Therrell, $P h D^{2}$, and Maria Ayoob, $M P H^{1}$

\begin{abstract}
Purpose: To inform current policy debate regarding the public health role in long-term follow-up for individuals with disorders identified through state newborn testing efforts, by identifying and assessing key challenges, quality assurance activities, and long-term follow-up perceptions of state newborn screening programs. Methods: A 23-question, web-based survey sent to newborn screening programs in all 50 states and Washington, DC, during January and February, 2005. Results: Many U.S. newborn screening programs do not currently engage in structured long-term follow-up for newborns with diagnosed disorders. The newborn screening programs that do long-term follow-up face various challenges that may impact their ability to perform it effectively. Barriers include a lack of comprehensive quality assurance practices, outsourcing, financial constraints, and perceived communication problems with providers who treat these patients. Conclusions: A more in-depth analysis of the desired and feasible roles that should be played by newborn screening programs in long-term follow-up is needed. The wide variability within programs regarding the structure and implementation of long-term follow-up, and the relative absence of long-term follow-up systems components in some newborn screening programs, poses an interesting question regarding responsibility for evaluation of longer-term outcomes associated with newborn testing and disorder diagnosis. Genet Med 2006:8(9):563-570.
\end{abstract}

Key Words: newborn screening, long-term follow-up, state policy, public health

Many states are expanding their newborn screening (NBS) to include additional metabolic disorders as a result of improved screening technology. A fully functional NBS system includes education, testing, short-term follow-up (STFU), confirmatory diagnoses for newborns with abnormal screens, referral and connection of the child to treatment, ongoing medical management, and program evaluation/quality assurance. ${ }^{1,2}$ This system includes the state NBS program as one stakeholder interacting with other state child health programs, primary care and specialty providers, families, and disease-specific interest groups. The components of medical management for newborns with a positive diagnosis, program evaluation, and quality assurance fit into what has been termed long-term follow-up (LTFU). ${ }^{2,3}$

LTFU is the component of the newborn screening system that ensures that individuals with a diagnosed disorder receive timely, appropriate care. ${ }^{3}$ It differs from short-term follow-up which addresses the entire population of individuals with abnormal test results and includes all activities up to and including confirmatory diagnosis. By nature of its focus, LTFU implies activities performed through a child's adolescence and, for select disorders,

\footnotetext{
From the ${ }^{1}$ Department of Health Policy, Management, and Behavior, School of Public Health, University at Albany, SUNY, Albany, New York; ${ }^{2}$ National Newborn Screening and Genetics Resource Center, Austin, Texas.

Timothy Hoff, Department of Health Policy, Management, and Behavior, UAlbany School of Public Health, Room 181, GEC Building, 1 University Place, Rensselaer, NY 12144.

Submitted for publication January 9, 2006.

Accepted for publication June 27, 2006.
}

DOI: 10.1097/01.gim.0000237790.54074.3d into adulthood. Ideally, the individual's "medical home" provides this ongoing care, which may involve the primary care physician, pediatric subspecialist, genetic counselor, clinical geneticist, and others. A "medical home" is defined as a regular and consistent source of care for a patient that is accessible, family-centered, comprehensive, and culturally competent. ${ }^{1}$ Some screening programs include themselves as a part of LTFU primarily by overseeing and coordinating the ongoing care available in the public health system.

LTFU is recognized as a key part of the newborn screening system which enhances its value as a public health activity. However, emphasis by policy makers has not traditionally been placed on LTFU. Rather, it has been placed on the more visible system components leading to initial diagnosis, including the extent to which testing laboratories meet quality assurance standards, the availability of laboratory-based resources (e.g., technology, equipment, staffing), the validity of tests and testing processes, improvements in short-term communication between institutions collecting specimens and the testing laboratory, and policies related to communicating positive test results and receiving confirmation of diagnosis. ${ }^{4}$ In short, traditional emphasis has been placed on STFU.

\section{Key aspects of a fully functional state newborn screening system}

From a public health perspective, it can be argued that NBS programs should play a meaningful role in LTFU. According to recently released guidelines for LTFU: "Long-term follow-up is a mechanism for determining if the newborn screening system is accomplishing its intended goal of improving health outcomes. Long-term follow-up refers to an infrastructure 
with the capacity for periodic monitoring of selected outcome indicators appropriate for evaluating the efficacy of newborn screening. Data obtained through long-term follow-up can be useful in improving and refining the newborn screening system. Long-term follow-up may include facilitation of services to ensure coordinated, comprehensive health care." ${ }^{5}$

This definition of LTFU connotes activities in the area of evaluation, quality assurance, and policy development that NBS programs are, by nature of their centrality in the larger public health system in a state, in strategic position to conduct. $^{3}$ In order to adequately contribute to meeting these follow-up guidelines, however, it is important for NBS programs to be cognizant of the issues surrounding LTFU and to take a leadership role, perhaps in tandem with the providers who serve these patients, in finding solutions that lead to more comprehensive LTFU. For these reasons, every NBS program could be expected to engage in one or more of the following LTFU activities: implementation, coordination, and oversight. In addition, there should be adequate resources related to staffing, information technology, and quality assurance to conduct LTFU activities in NBS programs. Financial resources are also crucial to a fully functioning state newborn screening system. For example, a recent General Accounting Office Survey found that states with newborn screening fees supported approximately two-thirds of their newborn screening activities with those fees. ${ }^{6}$

An effective quality assurance (QA) approach to LTFU is also a necessary systems component within newborn screening programs. This approach would include standardized practices and processes with appropriate oversight, the use of evidence and feedback to monitor and improve the LTFU processes and their oversight, evaluation of benchmarks and measurable indicators to assess performance, cost-benefit analysis of the various LTFU activities, and the ability to track diagnosed patients as they receive care over time. ${ }^{7,8}$ Some degree of conformity in how LTFU is conceptualized across NBS programs, regardless of the type of disorder, would assist in standardizing access to long-term medical management activities throughout the country. Currently, each program is left to define the extent to which it is involved in implementing and managing the activities related to LTFU.

The specific model a NBS program uses to conduct its LTFU can shape the integrity and quality of the entire NBS apparatus within a jurisdiction. For example, some NBS programs may internalize the LTFU function, performing most of the oversight and QA activities themselves. Others may outsource LTFU to direct care providers (e.g., academic medical centers) or other service providers. Generally, less centralized oversight and control exists in situations where governmental entities outsource functions completely. ${ }^{9}$ In addition, state newborn screening programs that perform LTFU in-house may have an enhanced ability to coordinate the full spectrum of laboratory testing and access to both STFU and LTFU which, in combination, define the newborn screening system of care. Along with the specialty and primary care providers who provide direct care to individuals, this strong in-house attention to LTFU by
NBS programs facilitates higher quality, more fully integrated services delivered to patients, their families, and physicians.

Finally, it is important to understand, from the perspective of those who oversee follow-up in NBS programs, the relative importance of the different challenges to conducting more intensive LTFU oversight and evaluation. Some of these challenges have been identified in the literature and include foremost the difficulty of identifying the correct medical home for the screened newborn. Other challenges include: timeliness of confirmatory testing to resolve abnormal screening test results; communication between health care providers, families, and the NBS program; appropriate and comprehensive financial resources; consensus as to the definition of LTFU; and the degree to which clinicians and patients desire to be formally involved in follow-up activities. ${ }^{1,2,10-13}$

In evaluating the potential for states to have well functioning LTFU systems, and for understanding the potential for a uniform national NBS system relative to LTFU, it is important to gain descriptive data that identifies the extent to which state newborn screening programs: 1) Engage in, oversee, and conceptualize LTFU activities across different disorders; 2) use appropriate quality assurance mechanisms in performing LTFU; 3) have resources at their disposal for LTFU activities; and 4) assess the different types of challenges that exist locally relative to conducting LTFU more effectively. This research need is highlighted by the rapid expansion of newborn screening now occurring in most states. ${ }^{4}$ Implementing expanded screening quickly, even for rarer disorders, without examining the prospects for key parts of the LTFU system to be in place and functioning, creates a risk of diminished potential in regards to the public health value of NBS expansion.

\section{DATA AND METHODS}

\section{Survey and sample}

A 23-question survey was prepared and sent to newborn screening programs in all 50 states and the District of Columbia (DC). The same survey was administered in both webbased and mail formats. The web-based version of the survey was sent to the e-mail addresses for both laboratory and follow-up screening program contacts listed in the most recent contact list maintained by the National Newborn Screening and Genetics Resource Center. ${ }^{14}$ However, only follow-up coordinators were asked to reply, unless there was a state-specific situation in which the lab coordinator also managed the follow-up function. Three surveys were actually completed by state newborn screening lab coordinators. Only two respondents chose to reply by mail. The remainder completed the online survey.

The survey was administered during January and February, 2005. The web-based survey was sent first to screening program contacts. An initial e-mail from the first author, containing a link to the survey, was sent to each contact. Several follow-up e-mails were sent to non-respondents over the course of the next three weeks asking them to complete the online 
survey. Approximately two weeks after the initial e-mail, a copy of the survey was mailed to all non-respondents.

The survey focused solely on the practices and perceptions of LTFU from the point of view of NBS programs. The complete survey is available by contacting the first author. Questions in the survey asked respondents to categorize the components of LTFU, whether or not their programs engaged in any LTFU practices, how they viewed specific LTFU activities across different groups of disorders, the extent to which appropriate LTFU quality assurance practices were available (such as computerized tracking systems), whether their LTFU performance was evaluated, the resources available for LTFU, perceived barriers to conducting LTFU, and concerns about LTFU in relation to NBS expansion. Respondents were provided with a list of activities related to literature definitions of LTFU, as described above, and asked whether or not they performed any of those activities in their state programs. The survey was pilottested on a group of 12 individuals at the first author's school of public health, in addition to several individuals working in the field of genetics. Minor modifications were made to the survey based on the pilot test, mostly in the way questions were worded.

\section{Statistical analysis}

Completed surveys were exported to an SPSS data file for cleaning and analysis. SPSS 13.0 was used for analysis. Survey responses were coded numerically in the SPSS file. To round out the data set, three additional variables were taken from the National Newborn Screening Information System (NNSIS), maintained by the National Newborn Screening and Genetics Resource Center: the number of live births for each state; the total number of confirmed disorder diagnoses within each state since screening began; and the newborn screening fees currently charged. Values for each of these variables were entered into the SPSS data file directly from the NNIS data set. In addition, the number of required conditions for testing in each state, during February and October, 2005, were also entered as variables in the SPSS data set.

Analysis was conducted using a combination of univariate and bivariate statistical operations. These included descriptives such as frequencies, means, and standard deviations; analysis of variance using independent and paired sample $t$ tests; and cross-tabulations, using the $\chi^{2}$ test of association. For analysis of variance, pairwise deletion was used to address missing cases, which is appropriate when the data are assumed to be missing randomly. ${ }^{15}$ In other instances, where frequencies and descriptive statistics were analyzed, missing data were also treated as random. In general, there were no systematic patterns observed across surveys in relation to what types of data were missing. Almost all of the questionnaires met the same level of completeness. However, there were some completed surveys that had blank answers, particularly in relation to the question asked about how similar or different the LTFU process for various disorders appeared to respondents.

\section{RESULTS}

Surveys were completed and returned by 45 of 50 states, and DC. Twenty-three respondents indicated that at present they do not engage in any LTFU activities or oversight within their NBS program. The remaining 23 respondents indicated that they perform some level of LTFU oversight and activities beyond confirmatory diagnosis (Table 1). The LTFU activities engaged in by screening programs varied and involved: ensuring ongoing access to a medical home for individuals with diagnosed disorders; ensuring that appropriate, ongoing treatment and management of disorders is provided; timely identification and implementation of needed changes in treatment and management plans; and availability of support services such as transportation and information. These activities are consistent with the descriptions of LTFU discussed in the NBS literature. ${ }^{3,5}$

There were no systematic relationships observed in the data between whether a program engaged in LTFU and population size (measured in live births), number of required conditions for testing, number of total confirmed cases in the state since testing began, and size of NBS fee. States as small as Vermont and as large as California reported that they engaged in LTFU for newborns with diagnosed disorders. While screening fees have been cited as a key funding source for NBS program activities, ${ }^{6}$ fees in programs conducting LTFU ranged from $\$ 0-78$, with a median screening fee of $\$ 36$. NBS programs engaged in LTFU also were found to be expanding newborn screening at the time of the survey, in several cases doubling the number of disorders mandated for testing (Table 1).

Several different models for conducting LTFU were reported (Table 2). Only 6 of 23 (26\%) states reported that LTFU was performed completely in-house, i.e., all LTFU activities were done directly by the NBS program and its staff. The more popular LTFU model involved screening programs completely contracting LTFU functions to medical centers or other outside entities. Forty-three percent of programs performing LTFU reported contracting it out fully. An additional 4 NBS programs $(17 \%)$ reported a mixed model of LTFU, with some functions retained within the screening program and others contracted out. Three smaller programs reported other groups within their state health department, or another state agency, performing LTFU activities in lieu of the NBS program. Programs that reported contracting out LTFU activities had fees similar to programs doing LTFU completely in-house. However, they screened for fewer conditions and had fewer confirmed cases over time than programs performing LTFU completely in-house.

Variation was observed in the degree to which respondents felt that LTFU was similar or different across specific disorders. Respondents were asked to label the similarity or differences in LTFU across 11 commonly tested disorders (galactosemia [GAL], maple syrup urine disease [MSUD], phenylketonuria [PKU], homocystinuria [HCY], biotinidase deficiency [BIO], congenital adrenal hyperplasia [CAH], cystic fibrosis [CF], congenital hypothyroidism $[\mathrm{CH}]$, sickle-cell disease [SCD], 
Table 1

NBS programs reporting that they have a LTFU component in place $(\mathrm{N}=23)$

\begin{tabular}{|c|c|c|c|c|c|c|}
\hline $\begin{array}{c}\text { NBS } \\
\text { program }\end{array}$ & $\begin{array}{l}\text { Births } \\
(2003)^{a}\end{array}$ & $\begin{array}{l}\text { Required conditions } \\
\text { February, } 2005^{b}\end{array}$ & $\begin{array}{l}\text { Required conditions } \\
\text { October, } 2005^{b}\end{array}$ & $\begin{array}{l}\text { Percent change in required } \\
\text { conditions (Feb. - Oct.) }\end{array}$ & $\begin{array}{l}\text { Reported screening fee }(\$) \\
\text { October, } 2005^{b}\end{array}$ & $\begin{array}{l}\text { Number of confirmed } \\
\text { cases }^{c} \text { October, } 2005\end{array}$ \\
\hline Arizona & 90,967 & 8 & 11 & 38 & 20.00 & 831 \\
\hline Arkansas & 37,784 & 4 & 10 & 150 & 14.83 & 813 \\
\hline California & 540,997 & 37 & 47 & 27 & 78.00 & 8,310 \\
\hline Colorado & 69,339 & 7 & 50 & 614 & 53.25 & 980 \\
\hline Florida & 212,250 & 5 & 11 & 120 & 15.00 & 4,431 \\
\hline Hawaii & 18,100 & 35 & 44 & 26 & 47.00 & 273 \\
\hline Illinois & 182,495 & 34 & 47 & 38 & 47.00 & 4,753 \\
\hline Iowa & 38,174 & 39 & 52 & 33 & 56.00 & 283 \\
\hline Louisiana & 65,040 & 5 & 9 & 80 & 18.00 & 599 \\
\hline Maryland & 74,930 & 34 & 44 & 29 & 42.00 & 2,409 \\
\hline Michigan & 131,094 & 12 & 15 & 25 & 55.72 & 2,511 \\
\hline Minnesota & 70,050 & 37 & 53 & 43 & 61.00 & 422 \\
\hline Montana & 11,422 & 4 & 9 & 125 & 39.34 & 53 \\
\hline Nebraska & 25,917 & 7 & 13 & 86 & 30.75 & 277 \\
\hline Nevada & 33,647 & 35 & 43 & 23 & 60.00 & 41 \\
\hline $\begin{array}{l}\text { North } \\
\text { Carolina }\end{array}$ & 118,323 & 28 & 34 & 21 & 10.00 & 438 \\
\hline $\begin{array}{l}\text { North } \\
\text { Dakota }\end{array}$ & 7,972 & 41 & 43 & 5 & 36.00 & 193 \\
\hline Oklahoma & 50,981 & 8 & 11 & 38 & 10.50 & 640 \\
\hline Texas & 377,476 & 5 & 8 & 60 & 19.50 & 6,890 \\
\hline Vermont & 6,589 & 22 & 31 & 41 & 33.30 & 126 \\
\hline Virginia & 101,254 & 10 & 30 & 200 & 32.00 & 2,168 \\
\hline Washington & 80,489 & 10 & 12 & 20 & 64.40 & 359 \\
\hline $\begin{array}{l}\text { West } \\
\text { Virginia }\end{array}$ & 20,935 & 4 & 10 & 150 & 0.00 & 141 \\
\hline
\end{tabular}

${ }^{a}$ Obtained from the National Center for Health Statistics.

${ }^{b}$ Obtained from the National Newborn Screening and Genetics Resource Center (NNSGRC).

${ }^{c}$ Confirmed cases, defined as all total confirmed disorders identified in a state from commencement of screening for various disorders in that state. Data obtained from the National Newborn Screening Information System, NNSGRC.

medium chain acyl-CoA dehydrogenase [MCAD], and hearing screening [HEAR]). Eighteen of 33 NBS programs responded that LTFU for hearing screening was uniquely different from LTFU for the other 10 disorders. However, only 9 of 41 stated that LTFU for sickle-cell disease was uniquely different from LTFU for the other 10 disorders. High levels of NBS program agreement were seen in relation to viewing LTFU for CF and SCD as similar (26/36), LTFU for CAH and CH (both endocrine disorders) as similar (23/41), and LTFU for PKU, MSUD, and HCY (all metabolic disorders) as similar (26/37). In addition, 31 of 43 programs responding believed that at least 5 of the 11 conditions asked about had LTFU activities that were similar in scope and substance. These findings indicate that there was agreement within and across NBS programs in terms of the similarity of LTFU for select disorders, especially those falling into the same specialty category, e.g., endocrine disorders.

\section{Quality assurance capacity and practices in NBS programs doing LTFU}

In the NBS programs engaged in LTFU, there was wide variation in terms of the presence or use of quality assurance mechanisms (Table 3). Over half of these respondents reported having standardized processes or procedures in place for conducting LTFU in their program. In addition, $62 \%$ reported use of a computerized patient tracking system to aid them in LTFU oversight and activities. However, much smaller percentages indicated that they had a formal evaluation plan to assess and improve their program's performance in the LTFU 
Table 2

Models of LTFU reported by NBS programs with a LTFU component $(\mathrm{N}=23)$

\begin{tabular}{|c|c|c|c|c|c|}
\hline LTFU model & NBS program & Births $^{a}$ & Conditions $^{a}$ & Screening fee ${ }^{a}$ & Cases $^{a}$ \\
\hline \multirow[t]{6}{*}{ In-house completely } & Arkansas & \multirow{15}{*}{56,552} & \multirow{14}{*}{27} & \multirow{14}{*}{30.75} & \multirow{15}{*}{1611} \\
\hline & California & & & & \\
\hline & Iowa & & & & \\
\hline & Maryland & & & & \\
\hline & Texas & & & & \\
\hline & West Virginia & & & & \\
\hline \multirow[t]{10}{*}{ Contracts out } & Arizona & & & & \\
\hline & Colorado & & & & \\
\hline & Florida & & & & \\
\hline & Louisiana & & & & \\
\hline & Montana & & & & \\
\hline & Nebraska & & & & \\
\hline & Nevada & & & & \\
\hline & Oklahoma & & & & \\
\hline & Virginia & & & & \\
\hline & Washington & 67,190 & 12 & 31.38 & 620 \\
\hline \multirow[t]{4}{*}{ Some in-house, some contracted out } & Illinois & & & & \\
\hline & Michigan & & & & \\
\hline & Minnesota & & & & \\
\hline & North Carolina & 124.709 & 41 & 5136 & 1475 \\
\hline \multirow[t]{3}{*}{ Other LTFU model } & Hawaii & & & & \\
\hline & North Dakota & & & & \\
\hline & Vermont & 7,792 & 43 & 36.00 & 193 \\
\hline
\end{tabular}

${ }^{a}$ Median for subgroup of states identified. Data obtained from NNSGRC (required conditions, fee, and confirmed cases by state, October, 2005); National Center for Health Statistics (Births, 2003).

Table 3

Quality assurance elements in place across NBS programs conducting LTFU $(\mathrm{N}=21)$

\begin{tabular}{lcr}
\hline \multicolumn{1}{c}{ QA elements in place } & Percent of NBS programs conducting LTFU $(\%)$ & ${\text { Screening fee in NBS program }(\$)^{a}}^{\circ}$ \\
\hline Standardized process or procedure in place for conducting LTFU & 57 & 37.67 \\
Use of computerized tracking system to conduct LTFU & 62 & 47.00 \\
Formal evaluation plan in place to evaluate LTFU & 19 & 40.67 \\
Program tracks the costs of performing LTFU activities & 33 & 36.00 \\
All four QA components in place & 14 & 39.34 \\
Three QA components in place & 5 & 42.00 \\
Two QA components in place & 33 & 36.00 \\
One QA component in place & 24 & 60.00 \\
No QA components in place & 24 & 20.00 \\
\hline
\end{tabular}

${ }^{a}$ Median screening fee, from October, 2005 NNSGRC data, for states in the particular QA subgroup.

area, and that they were able to track the costs (and benefits associated with those costs) of their LTFU activities. When examined as a group of QA elements, only 14\% (3 of 21) of programs had all four of the named QA elements in place, one program had three in place, and 33\% (7 of 21) had two QA elements in place. Approximately 1 in 4 of respondents reported none of the $4 \mathrm{QA}$ elements being used in their programs. 
A subgroup analysis was performed to examine whether or not funding capacity was related to the presence or absence of QA elements in NBS programs. As Table 3 shows, the lowest median NBS fee was for the cluster of programs that reported none of the four QA elements in place. The highest median fee was for programs that had only one QA element in place, while median fees were similar across clusters of programs with two, three, or four QA elements in place. In general, median fees ranged from $\$ 30-40$ for states possessing any type of QA component for their LTFU activities. This was slightly higher than the overall median fee of $\$ 30$ for the sample as a whole.

\section{Perceived barriers and concerns related to LTFU}

Respondents were asked to rate different types of barriers to conducting LTFU in NBS programs (Table 4). A variety of work process, structural, and cultural barriers were assessed and compared to one another in terms of level of perceived importance by the NBS programs. Not surprisingly, "insuffi- cient financial resources" was identified as the most important LTFU barrier in NBS programs. Eighty percent of all respondents, whether or not they performed LTFU, identified this barrier as "extremely important." In answering a separate survey question about whether or not resources in their NBS program were adequate to engage in LTFU, only $13 \%$ of all respondents "agreed" or "strongly agreed" with the statement that resources were adequate. It is worth noting that no significant associations were found between the financial resources barrier, perceptions of resource adequacy, and the actual size of the NBS fee in a given state. In addition, programs identified "lack of clinician interest in screening program follow-up" and "communication breakdowns between physicians and the NBS program" as meaningful LTFU barriers. Forty-one and 50 percent of respondents, respectively, rated these two barriers as "extremely important." The communications breakdown barrier correlated significantly with "difficulty of locating a patient's medical home," suggesting that part of the perceived

Table 4

Perceived barriers to conducting adequate LTFU in NBS programs $(\mathrm{N}=46)$

\begin{tabular}{|c|c|c|c|c|}
\hline LTFU barrier & $\begin{array}{l}\text { Mean level of } \\
\text { importance, all NBS } \\
\text { programs }^{a}\end{array}$ & $\begin{array}{l}\text { Percent who identify } \\
\text { as extremely } \\
\text { important }\end{array}$ & $\begin{array}{l}\text { Percent who } \\
\text { identify as } \\
\text { important }\end{array}$ & Other findings \\
\hline \multicolumn{5}{|l|}{ Work Process Barriers: } \\
\hline $\begin{array}{l}\text { Difficulty of locating patient's } \\
\text { "medical home" }\end{array}$ & 1.91 & 37 & 39 & $\begin{array}{l}\text { Significant correlation with "communication } \\
\text { breakdowns between physicians and } \\
\text { screening program" barrier }(\mathrm{r}=0.434 \\
P=0.004)\end{array}$ \\
\hline $\begin{array}{l}\text { Lack of timeliness in clinician } \\
\text { confirmation of disorder } \\
\text { diagnosis }\end{array}$ & 1.87 & 42 & 31 & $\begin{array}{l}\text { Significant correlation with "lack of patient } \\
\text { interest in screening program follow-up" } \\
\text { barrier }(\mathrm{r}=0.488, P=0.001)\end{array}$ \\
\hline $\begin{array}{l}\text { Communication breakdowns } \\
\text { between physicians and } \\
\text { screening program }\end{array}$ & 1.73 & 50 & 30 & \\
\hline $\begin{array}{l}\text { Variation in LTFU activities } \\
\text { needed for different disorders }\end{array}$ & 2.40 & 13 & 38 & \\
\hline Mean for work process barriers & 1.98 & 36 & 35 & \\
\hline \multicolumn{5}{|l|}{ Structural Barriers: } \\
\hline Insufficient financial resources & 1.32 & 80 & 11 & $\begin{array}{l}\text { Mean level of importance is significantly } \\
\text { different than each and every other } \\
\text { barrier's mean level of importance }\end{array}$ \\
\hline $\begin{array}{l}\text { Lack of program control over } \\
\text { monitoring of LTFU activities }\end{array}$ & 2.07 & 31 & 31 & \\
\hline Mean for structural barriers & 1.70 & 56 & 21 & \\
\hline \multicolumn{5}{|l|}{ Cultural Barriers: } \\
\hline $\begin{array}{l}\text { Lack of patient interest in screening } \\
\text { program follow-up }\end{array}$ & 1.93 & 36 & 36 & \\
\hline $\begin{array}{l}\text { Lack of clinician interest in } \\
\text { screening program follow-up }\end{array}$ & 1.73 & 41 & 46 & $\begin{array}{l}\text { Significant correlation with "communication } \\
\text { breakdowns between physicians and } \\
\text { screening program" barrier }(\mathrm{r}=0.461 \\
P=0.002)\end{array}$ \\
\hline $\begin{array}{l}\text { Inability to define elements to be } \\
\text { included in LTFU }\end{array}$ & 2.29 & 29 & 22 & \\
\hline Mean for cultural barriers & 1.98 & 35 & 35 & \\
\hline
\end{tabular}

${ }^{a}$ Scored 1-4: 1 = extremely important, 2 = important, 3 = less important, $4=$ not very important. 
Table 5

Expansion concerns rated by NBS programs $(\mathrm{N}=46)$

\begin{tabular}{|c|c|c|c|c|}
\hline Expansion concern & $\begin{array}{l}\text { Percent rating extremely } \\
\text { important }\end{array}$ & $\begin{array}{l}\text { Percent rating } \\
\text { important }\end{array}$ & $\begin{array}{l}\text { Correlated with whether } \\
\text { state does LTFU? }\end{array}$ & $\begin{array}{l}\text { Correlated with model } \\
\text { used for LTFU? }\end{array}$ \\
\hline $\begin{array}{l}\text { Testing for disorders in which treatment } \\
\text { and management is uncertain }\end{array}$ & 28 & 28 & No & No \\
\hline $\begin{array}{l}\text { Ability to provide quality follow-up to } \\
\text { all individuals }\end{array}$ & 67 & 21 & No & No \\
\hline $\begin{array}{l}\text { Difficulty locating and tracking medical } \\
\text { homes }\end{array}$ & 33 & 33 & $\operatorname{Yes}^{a}(-0.350, P<0.05)$ & No \\
\hline $\begin{array}{l}\text { Difficulty getting needed information } \\
\text { from providers }\end{array}$ & 30 & 28 & No & No \\
\hline
\end{tabular}

${ }^{a}$ Statistic implies that states which do LTFU have a lower level of concern than states that do not do LTFU with "difficulty locating and tracking medical homes" in light of testing expansion.

communications barrier may involve difficulties for NBS programs in identifying patients' primary care provider.

NBS programs were also asked to give their opinions about several LTFU concerns related to expanded newborn testing (Table 5). The most important concern identified by respondents involved the ability to provide quality follow-up to all individuals with a confirmed disorder diagnosis. A lesser but still important concern involved perceived difficulties in locating and tracking patients' medical homes. However, programs that currently perform LTFU were less likely than ones not doing LTFU to label the medical home concern as "important" or "extremely important" (the negative, significant correlation noted in Table 5). No other relationships between an expansion concern and the scope and substance of state NBS programs' LTFU activities were found.

\section{DISCUSSION}

The study findings inform current practice and concerns in the LTFU component of state newborn screening programs. The results of this initial survey present a mixed picture of the challenges and barriers to LTFU faced by NBS programs. Perhaps the most important finding is that half of U.S. NBS programs do not currently engage in any type of LTFU activity past the confirmatory diagnosis phase. While this finding does not speak to whether other agencies or programs within a jurisdiction, outside of the NBS program, engage in LTFU, it shows increased system fragmentation since testing and STFU activities (which normally are integrated within the NBS program) are separated from LTFU, and therefore knowledge of the longer term outcomes of testing and disorder identification. It also implies that many programs simply may not perform much in the LTFU area, leaving this responsibility solely to providers who care directly for these patients. This suggests bigger picture questions such as how much responsibility for LTFU should exist at the state level, what kinds of LTFU activities should be performed by NBS programs, whether the level of LTFU responsibility should be uniform or vary across programs, and whether or not the health care system in a jurisdiction can absorb LTFU responsibilities (in cases where the NBS program does less in LTFU) given competing demands and restrictive time and budget realities.

Most NBS programs appear to suffer from a lack of quality LTFU oversight and direct knowledge of LTFU activities within their program coverage area. This may hinder their ability to improve the overall newborn screening system in their states as it relates to LTFU. First, most programs outsource LTFU to other nongovernmental entities such as academic medical centers. Almost half of programs doing any LTFU contract it out completely. Those contracting for LTFU appear to have fewer screening demands and lower fees than programs performing LTFU activities directly. Resource availability or the efficiencies gained from a larger screening operation may make it easier for a NBS program to do LTFU.

Second, there are few LTFU QA-related practices reported by most NBS programs. For example, only $14 \%$ of those doing any LTFU employed all four of the quality practices inherent in an effective systems approach, and one in four had none of the four QA elements in place. Yet, it appears that the range of QA practices present in a NBS program is not tied meaningfully to the availability of NBS fee funding to support those practices, except in the case where a NBS program has no QA practices in place. This raises the question of what other factors shape the presence or absence of QA practices around LTFU in a given NBS program. The ideal of a national LTFU systems approach is enhanced by the finding of a moderate level of conformity in how different NBS programs view LTFU across disorders. This may bode well for attempts to standardize or create uniform LTFU policies, guidelines, or performance benchmarks that encourage programs to do similar things, across clusters of disorders, to ensure aspects of care like medical home access, and that appropriate ongoing treatment and management is provided.

Not surprisingly, programs cite inadequate financial resources devoted to LTFU as the most important barrier undermining their ability to engage in LTFU activities. The results point to potentially wide variation in resource availability for LTFU in NBS programs. Given the range of NBS fees observed among programs engaged in some aspect of LTFU, it does not appear that resource capacity (to the extent such capacity is 
defined by NBS fee revenue) is presently the driving factor in the LTFU decision in many NBS programs. It cannot be ascertained from this study whether or not adequate resources for LTFU are available in NBS programs. However, this is a topic worthy of further investigation, in particular, the extent to which the scope and substance of a program's LTFU activities may be influenced by the amount of NBS fee revenue available at a given point in time. Other factors, such as characteristics of the relationship in a state between the NBS program and health care practitioners, are important areas of further investigation. To that end, the study shows that NBS programs have meaningful concerns related to how they interact with physicians around NBS issues, especially with respect to communication. In at least one other study, such concerns were identified on the opposite end by physicians in relation to state NBS programs. ${ }^{12}$

This study is limited in that it focuses only on state NBS programs. Additional research should seek to understand the full picture of LTFU barriers and practices within a state. However, focusing on the follow-up components of NBS programs, from which few systematic data have been collected in the past, is an appropriate first step in better assessing barriers to LTFU within a state generally. A second limitation is that survey responses are based on self-report from NBS program follow-up staff. To the extent these staff do not have accurate recall or knowledge of the topics covered in the survey questions, the responses may be subject to potential bias. At present, though, almost all of the data describing activities and performance in NBS systems, from testing through follow-up, rely upon reporting by NBS program staff within the programs. Thus, this form of data collection is not unusual or necessarily problematic. This survey is cross-sectional and represents only a snapshot of what NBS programs do and think about in relation to LTFU. Finally, the survey did not collect information on more "objective" NBS system performance measures. Thus, it remains an empirical question whether or not realities such as the presence or absence of LTFU within the state NBS program or the perceived barriers to LTFU in state NBS programs affects how the NBS system within a state performs. This is a logical future extension to the current research.

\section{ACKNOWLEDGMENTS}

Special thanks go to the National Newborn Screening and Genetics Resource Center, which provided portions of the data used in the study, as well as input on survey design and analysis of results.

\section{References}

1. Newborn Screening Task Force, American Academy of Pediatrics. Serving the family from birth to the medical home-Newborn screening: A blueprint for the future. Pediatrics 2000;106:383-427.

2. Therrell BL,. U.S. newborn screening policy dilemmas for the twenty-first century. Mol Genet Metab 2001;74:64-74.

3. AAP Newborn Screening Task Force. Serving the family from birth to the medical home. Newborn Screening: A blueprint for the future. Pediatrics 2000; 106 : 389-427.

4. Maternal and Child Health Bureau. Newborn screening: Toward a uniform screening panel and system. 2004. Available online at: ftp.hrsa.gov/mchb/genetics/screeningdraftforcomment.pdf. Accessed on March 6, 2006.

5. Clinical and Laboratory Standards Institute. Newborn screening follow-up: Proposed guideline. Available at: http://www.nccls.org/. Accessed December 21, 2005.

6. Dodd CJ, DeWine M. Newborn screening: Characteristics of state programs. Available at: http://www.gao.gov. Accessed March 20, 2005.

7. Harteloh PP. Quality systems in health care: A sociotechnical approach. Health Policy 2003;64:391-398

8. Spath P. Improve quality with systems thinking. Part 1. Hospital Peer Review 27:173$175,2002$.

9. Keane C, Marx J, et al. The perceived impact of privatization on local health departments. Am J Public Health 2002;92:1178-1180.

10. Saxena A. Issues in newborn screening. Genet Test 2003;7:131-134

11. Clayton EW. Issues in state newborn screening programs. Pediatrics 1992;90:641646.

12. Kim S, Lloyd-Puryear MA, Tonniges TF. Examination of the communication practices between state newborn screening programs and the medical home. Pediatrics 2003;111:120-126.

13. Mandl KD, Feit S, Larson C, Kohane IS. Newborn screening program practices in the United States: notification, research and consent. Pediatrics 2002;109:269-273.

14. Newborn screening programs in the U.S., October 2005. Available at: http://genes-r-us. uthscsa.edu. Accessed November 15, 2005.

15. Cohen J, Cohen P. Applied multiple regression/correlation analysis for the behavioral sciences. Second Edition. New Jersey: Lawrence Erlbaum, 1983. 